\title{
Using Zebrafish for Screening and Development of New Nicotinic and Dopaminergic Drugs
}

\section{R. Thomas Boyd*}

Department of Neuroscience, The Ohio State University College of Medicine, Columbus Ohio, USA

Zebrafish are a new vertebrate animal model with advantages for screening and development of therapeutic agents. Many biochemical pathways present in humans are conserved in zebrafish. Zebrafish embryos develop rapidly (first somite at about 10 hours of development compared to 9-10 days in the rat) outside of the mother with the potential for generating hundreds of embryos from a single mating. Zebrafish can be grown in plates for several days to allow easy observation and use in High-Throughput Screening (HTS). The early embryos are also transparent, providing the ability to observe specific cells or brain regions during development without the need to kill the animals. Embryogenesis is complete by 72 hours post fertilization (hpf) and most organs are fully developed at $96 \mathrm{hpf}$ [1]. A large number of mutants are available and much of the genome has been sequenced (http://www.sanger.ac.uk) which allows the genetic advantages of mice, but with a short generation time (2-3 months). Zebrafish neural development occurs in a well characterized pattern and well-defined molecular markers (antibodies, DNA probes) are available to help identify specific cells and brain regions. Transgenic zebrafish have been developed which express GFP in specific cells [2] and allow for the activity of specific neurons to be monitored in vivo [3]. The small size of zebrafish makes them ideal for use in 96 or 384 well plates. The cost to maintain zebrafish is a fraction of that for mice since they don't require feeding until 6-7 days post fertilization.

The use of zebrafish allows one to combine the ability to perform behavioral assays with HTS [4]. Many behavioral assays developed in other animals, and which are used to assay drugs targeted to several neurological diseases, are available in zebrafish [5]. These include Prepulse Inhibition (PPI), startle response, locomoter and learning assays. These can be performed on a higher scale and at much lower cost than in other vertebrates. The data collection and analysis from many of these tests can be automated [4]. Indeed, zebrafish can be used at several points in the drug discovery process. Zebrafish are ideal for testing drug toxicity on a large scale, thus saving much time, money and effort to further develop a compound with toxicity in vertebrates. In many cases, compounds with known toxicity in humans have a similar response in zebrafish [1]. Zebrafish have also been used in target confirmation after a lead compound has been identified. In vivo Structure Activity Relationship (SAR) studies in zebrafish have been performed [6]. Using in vivo screens during early stages of drug discovery could produce great savings in time, money and efficiency. Zebrafish have been used already in a large number of small molecule screens in both wild-type and mutant fish [1]. Zebrafish have also been used for targeted screens as well.

Methodologies are being developed for rapid behavior-based identification of neuroactive small molecules in zebrafish [7]. Thus it may be useful to screen and develop drugs to treat illnesses related to cholinergic and dopaminergic systems in zebrafish. Neuronal Nicotinic Acetylcholine Receptors (nAChRs) are involved in several CNS disorders such as addiction, Alzheimer's, epilepsy, and schizophrenia period [8].

nAChRs are pentameric structures $[9,10]$ which function as ligandgated ion channels permeable to $\mathrm{Na}^{+}, \mathrm{K}^{+}$and $\mathrm{Ca}^{2+}$ and are composed of multiple $\alpha$ and $\beta$ subunits. There are nine neuronal nAChR $\alpha$ subunit genes $(\alpha 2-\alpha 10)$ and three $\mathrm{nAChR} \beta$ subunit genes $(\beta 2-\beta 4)$ and distinct subtypes are formed from combinations of $\alpha$ and $\beta$ subunits. nAChR subtypes are designated as homo- or hetero-pentameric, depending on the subunit composition. Heteromeric receptors contain both $\alpha$ and $\beta$ subunits with the $\alpha 4 \beta 2$ receptor being the most prominent heteromer in the brain. Homomeric receptors are comprised of only a subunits with the $\alpha 7 \mathrm{nAChR}$ being the primary homomer. Each neuronal $\mathrm{nAChR}$ subtype also has a distinct pharmacology with both the $\alpha$ and $\beta$ subunits determining the sensitivity to agonists and antagonists $[11,12]$. Individual subtypes also have distinct ion channel properties such as conductance, rate of desensitization and channelopen time [13]. Neuronal nAChRs are often located presynaptically in the CNS and modulate release of important neurotransmitters such as norepinephrine, serotonin, Gamma Aminobutyric Acid (GABA), glutamate, and dopamine [14].

Cholinergic cells are distributed in zebrafish in a pattern similar to that seen in other vertebrate animals, present in sites including autonomic ganglia, the telencephalon, cranial motor nuclei, spinal cord, olfactory bulb, retina, tegmentum, and cerebellum [15]. We have cloned nine zebrafish neuronal nAChR cDNAs $(\alpha 2, \alpha 3, \alpha 4, \alpha 6, \alpha 7, \alpha 8$, $\beta 2, \beta 3, \beta 4)$. The structure of each $n A C h R$ gene has been determined by comparison of the cDNAs to the genome sequence. The $\alpha 2-\alpha 6$ and $\beta 2$ $\beta 4$ genes each have six exons as in other vertebrates while the $\alpha 7$ gene has ten as in other species. The expression patterns of the $\alpha 2, \alpha 4, \alpha 6, \alpha 7$, $\beta 3$ genes have been determined [16,17]. Many of these are expressed in regions analogous to structures in rats and mice. For example, the a6 nAChR subunit gene is expressed in zebrafish dopaminergic neurons as in mice. Zebrafish neuronal nAChRs subunits have been expressed in oocytes and the pharmacology of several combinations including $\alpha 3 \beta 4, \alpha 4 \beta 2$ and $\alpha 7$ determined [18]. For the most part, our work has shown that the pharmacology of cholinergic compounds in zebrafish is similar to that in other vertebrates and can be used to interpret behavioral assays used in HTS. Zebrafish are amenable to high throughput screening approaches to test compounds for effects on learning, memory, and anxiety. Zebrafish have been used to examine the anxiolytic effects of nicotine [19], spatial discrimination learning [20] and delayed spatial alternation [21].

Dopamine signaling is involved in addiction, schizophrenia and Parkinson's disease. Zebrafish orthologs of all four human dopamine receptors and associated enzymes have been identified [22]. Zebrafish have a well characterized set of catecholaminergic neurons, but the

*Corresponding author: R. Thomas Boyd, Department of Neuroscience, The Ohio State University College of Medicine 333 West Tenth Avenue, Columbus Ohio 43210 Tel: 614-292-4391; E-mail: Robert.Boyd@osumc.edu, boyd.16@osu.edu

Received August 17, 2012; Accepted August 18, 2012; Published August 20 2012

Citation: Boyd RT (2012) Using Zebrafish for Screening and Development of New Nicotinic and Dopaminergic Drugs. Mol Biol 1:e102. doi:10.4172/21689547.1000e102

Copyright: (c) 2012 Boyd RT. This is an open-access article distributed under the terms of the Creative Commons Attribution License, which permits unrestricted use, distribution, and reproduction in any medium, provided the original author and source are credited. 
homolog to the human mesencephalic dopamine neurons, has not been identified, although a possible region has been put forward [23]. Zebrafish have been used to screen for potential neuroprotective compounds in a zebrafish model of Parkinson's [24]. There is great potential to develop zebrafish disease models and behavioral assays which can be used in HTS for drugs which affect dopaminergic pharmacology.

The advantages of zebrafish for pharmaceutical screening [25] can be exploited to complement existing cell culture and mouse studies to test and develop new therapeutic compounds. Development and testing of compounds targeted to cholinergic and dopaminergic systems can take advantage of the use of zebrafish for HTS and development of disease models.

\section{References}

1. Delvecchio C, Tiefenbach J, Krause HM (2011) The zebrafish: a powerful platform for in vivo, HTS drug discovery. Assay Drug Dev Technol 9: 354-361.

2. Yoshida T, Mishina M (2003) Neuron-specific gene manipulations to transparen zebrafish embryos. Methods Cell Sci 25: 15-23.

3. Higashijima S, Masino MA, Mandel G, Fetcho JR (2003) Imaging neurona activity during zebrafish behavior with a genetically encoded calcium indicator. J Neurophysiol 90: 3986-3997.

4. Kokel D, Peterson RT (2008) Chemobehavioural phenomics and behaviourbased psychiatric drug discovery in the zebrafish. Brief Funct Genomic Proteomic 7: 483-490.

5. Colwill RM, Creton R (2011) Imaging escape and avoidance behavior in zebrafish larvae. Rev Neurosci 22: 63-73.

6. Hao J, Ho JN, Lewis JA, Karim KA, Daniels RN, et al. (2010) In vivo structure activity relationship study of dorsomorphin analogues identifies selective VEGF and BMP inhibitors. ACS Chem Biol 5: 245-253.

7. Kokel D, Bryan J, Laggner C, White R, Cheung CY, et al. (2010) Rapid behavior-based identification of neuroactive small molecules in the zebrafish. Nat Chem Biol 6: 231-237.

8. Gotti C, Zoli M, Clementi F (2006) Brain nicotinic acetylcholine receptors: native subtypes and their relevance. Trends Pharmacol Sci 27: 482-491.

9. Cooper E, Couturier S, Ballivet M (1991) Pentameric structure and subunit stoichiometry of a neuronal nicotinic acetylcholine receptor. Nature 350: 235238 .

10. Anand R, Conroy WG, Schoepfer R, Whiting P, Lindstrom J (1991) Neurona nicotinic acetylcholine receptors expressed in Xenopus oocytes have a pentameric quaternary structure. J Biol Chem 266: 11192-11198.
11. Luetje CW, Patrick J (1991) Both alpha- and beta-subunits contribute to the agonist sensitivity of neuronal nicotinic acetylcholine receptors. J Neurosci 11 : 837-845

12. Harvey SC, Luetje CW (1996) Determinants of competitive antagonist sensitivity on neuronal nicotinic receptor beta subunits. J Neurosci 16: 3798-3806.

13. Albuquerque EX, Pereira EF, Alkondon M, Rogers SW (2009) Mammalian nicotinic acetylcholine receptors: from structure to function. Physiol Rev 89 73-120.

14. Role LW, Berg DK (1996) Nicotinic receptors in the development and modulation of CNS synapses. Neuron 16: 1077-1085.

15. Clemente D, Porteros A, Weruaga E, Alonso JR, Arenzana FJ, et al. (2004) Cholinergic elements in the zebrafish central nervous system: Histochemical and immunohistochemical analysis. J Comp Neurol 474: 75-107.

16. Ackerman KM, Nakkula R, Zirger JM, Beattie CE, Boyd RT (2009) Cloning and spatiotemporal expression of zebrafish neuronal nicotinic acetylcholine receptor alpha 6 and alpha 4 subunit RNAs. Dev Dyn 238: 980-992.

17. Zirger JM, Beattie CE, McKay DB, Boyd RT (2003) Cloning and expression of zebrafish neuronal nicotinic acetylcholine receptors. Gene Expr Patterns 3 747-754.

18. Papke RL, Ono F, Stokes C, Urban JM, Boyd RT (2012) The nicotinic acetylcholine receptors of zebrafish and an evaluation of pharmacological tools used for their study. Biochem Pharmacol 84: 352-365.

19. Levin ED, Bencan Z, Cerutti DT (2007) Anxiolytic effects of nicotine in zebrafish Physiol Behav 90: 54-58.

20. Levin ED, Limpuangthip J, Rachakonda T, Peterson M (2006) Timing of nicotine effects on learning in zebrafish. Psychopharmacology (Berl) 184: 547-552.

21. Levin ED, Chen E (2004) Nicotinic involvement in memory function in zebrafish Neurotoxicol Teratol 26: 731-735.

22. Klee EW, Schneider H, Clark KJ, Cousin MA, Ebbert JO, et al. (2012) Zebrafish a model for the study of addiction genetics. Hum Genet 131: 977-1008.

23. Rink E, Wullimann MF (2001) The teleostean (zebrafish) dopaminergic system ascending to the subpallium (striatum) is located in the basal diencephalon (posterior tuberculum). Brain Res 889: 316-330.

24. McKinley ET, Baranowski TC, Blavo DO, Cato C, Doan TN, et al. (2005) Neuroprotection of MPTP-induced toxicity in zebrafish dopaminergic neurons. Brain Res Mol Brain Res 141: 128-137.

25. Langheinrich U, Hennen E, Stott G, Vacun G (2002) Zebrafish as a mode organism for the identification and characterization of drugs and genes affecting p53 signaling. Curr Biol 12: 2023-2028. 